\title{
The Meaning of the Sampling of the ZPPR Canisters and Proposed New Surveillance Operating Instructions
}

Charles W. Solbrig

January 2007

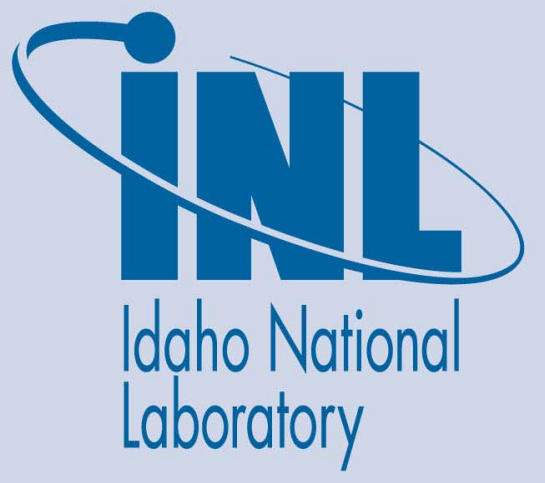

The INL is a U.S. Department of Energy National Laboratory operated by Battelle Energy Alliance 
INL/EXT-05-00696

\section{The Meaning of the Sampling of the ZPPR Canisters and Proposed New Surveillance Operating Instructions}

Charles W. Solbrig

January 2007

Idaho National Laboratory

Idaho Falls, Idaho 83415

Prepared for the

U.S. Department of Energy

Office of Nuclear Energy

Under DOE Idaho Operations Office

Contract DE-AC07-05ID14517 


\begin{abstract}
Analysis of the sample data taken from the ZPPR canisters containing Uranium plate fuel indicates that (as of February 2004) hydriding could be occurring in 35 of them. Since there appears to be no way of determining that a getter is functional, the getters in all the canisters should be replaced now (unless canister residence time can be determined) to prevent further hydriding. In addition, the surveillance procedure should be modified. Canisters to be inspected should be selected sequentially, 12 each quarter resulting in all being opened once every five years. Three of the 12 should be sampled and results reported before opening any of the canisters. Water vapor and pressure should be measured as well as the current hydrogen, oxygen, and nitrogen. Then all 12 canisters should be opened for physical evaluation of the plate conditions and correlation with the sample measurements. The getters should be replaced at each inspection ensuring that no getter is used more than five years. The data should be analyzed each year and a conclusion made on the adequacy of the surveillance procedure and modifications made if it is inadequate.
\end{abstract}




\section{CONTENTS}

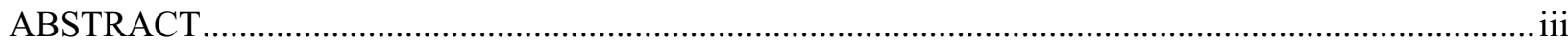

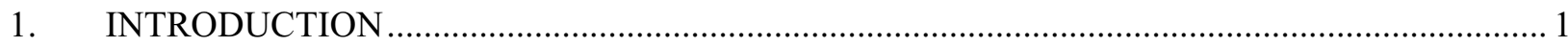

2. ESTIMATE OF THE CONDITION OF ZPPR FUEL PLATES AND PROBABLE HAZARDS BASED ON CANISTER SAMPLE DATA …...................................................... 3

3. CANISTER CONDITIONS AND ACTIONS TO BE TAKEN BASED ON SAMPLE

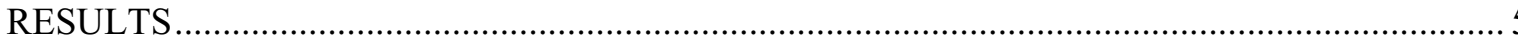

3.1 Actions Which Should be Taken Based on the Gas Samples Taken with the

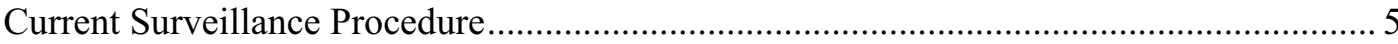

3.2 Actions Which Should be Taken Based on the Gas Samples Taken with the

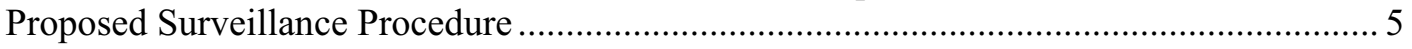

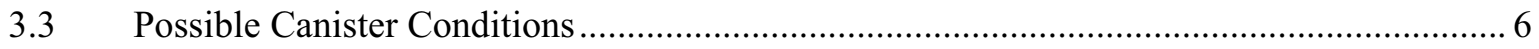

4. ATMOSPHERE OF THE CANISTERS AND FUNCTION OF THE GETTERS …....................... 9

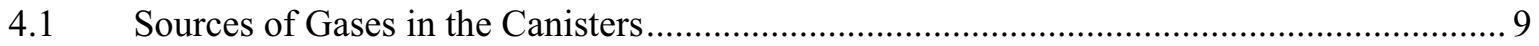

4.2 Requirement of Getter Placement in All Canisters and Replacement Period....................... 9

4.3 Important Note: Getter Does Not Consume Oxygen if There is no Hydrogen ................... 10

5. DESCRIPTION OF THE NEW SURVEILLANCE PROGRAM WHICH MINIMIZES

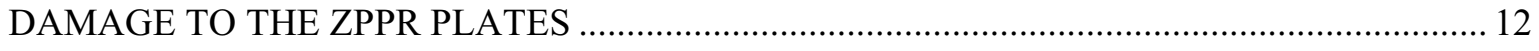

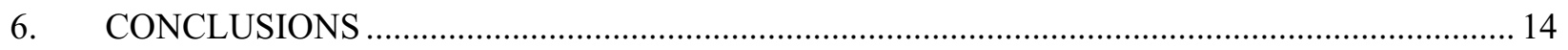

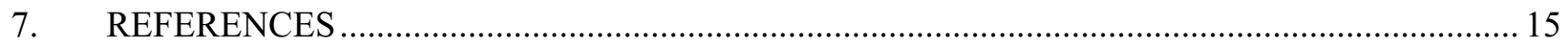

Appendix A — Detailed Comments on the Data Sheets ................................................................... 19

TABLES

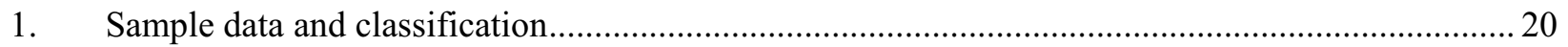

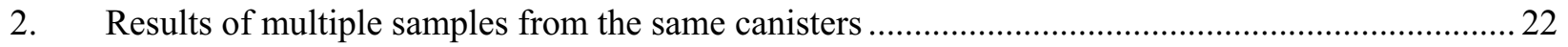




\section{Report on the Meaning of the Sampling of the ZPPR Canisters and Proposed New Surveillance Operating Instructions}

\section{INTRODUCTION}

This report first analyzes the data obtained from the sampling of the ZPPR canisters and presents conclusions as to the meaning of the data. The principal conclusion of this analysis is that plates in many of the canisters are still hydriding (as of February 2004) and that the surveillance program needs to be changed to prevent further degradation. The report next presents a description of the actions which should be taken based upon the sample results with the current surveillance procedure as well as the new suggested surveillance procedure. In addition possible atmospheres which could occur in a canister are described, even ones that have not been observed so far and may never be. The sources of gases in the canisters atmosphere and the characteristics of the getter are next described. The latter shows that oxygen is not consumed by the getter if no hydrogen is present. Finally, new operating instructions are proposed to aid in determining the chemistry occurring in the canisters, something which the current surveillance operating instructions do not do. This latter is accomplished without significant additional work by selecting canisters for sampling and observation in an ordered manner rather than by random.

There appears to be no way to have simultaneous high concentrations of hydrogen and oxygen in a closed (non leaky) container because the canisters are overpressured with dry nitrogen which inhibits the reactions. There have been cases in the literature (See Solbrig, 1994) where enough hydrogen was produced in a closed container with moist air as a cover gas that deflagrated but not when overpressured by a dry inert gas. Therefore, the risk of hydrogen oxygen combustion in the canisters is small.

There are 231 canisters containing useable and unusable uranium plates clad in 0.005 in. thick stainless steel clad with porous end caps. The porous end caps allow the gas atmosphere access to the uranium metal so the oxidation and hydriding reactions are completely inhibited only when there is perfectly dry nitrogen in the atmosphere.

Storage of the ZPPR plates, in general, is not a safety issue. Only under the most unusual circumstances could an explosion occur when a closed container is being moved. Sufficient hydride powder and oxygen would have to be in the canister when it is being moved or dropped so the hydride powder could disperse in the air to react spontaneously. Upon closure, the canisters are evacuated and pressurized to six psig with nitrogen so the only source of hydride and oxygen in the canisters would be from nitrogen leaking down to atmospheric pressure and then atmospheric pumping to bring in air and moisture. Any air inleakage of air due to atmospheric pumping brings in moisture and oxygen in the atmosphere which reacts with the uranium to produce uranium hydride and oxide through the corrosion cycle leaving only nitrogen in the gas. This degrades the plates so the main issue is plate degradation.

A slight safety issue exists in opening the canisters in air when there is uranium hydride present in the canister. The only indicator of hydride in the canister before it is opened would be hydrogen in the atmosphere. However, the canisters are not sampled before they are opened. Only three containers are sampled per quarter and these are not apparently the ones that are opened. This does not provide much information about the atmosphere in all the containers. This has not been much of a safety problem since the canisters have been opened with only minor flashing occurring occasionally. 
The main objective of the surveillance program is to protect the undamaged plates from deterioration in terms of oxidation and hydriding. As will be seen in the following section, the data show that the current surveillance program is not preventing hydriding so the program needs to be modified. 


\section{ESTIMATE OF THE CONDITION OF ZPPR FUEL PLATES AND PROBABLE HAZARDS BASED ON CANISTER SAMPLE DATA}

The current operating procedure requires that any sampled canister that contains more than $3 \%$ hydrogen or $7 \%$ oxygen is to be opened in an inert atmosphere. This restriction is not necessary since these hydrogen or oxygen concentrations do not present a danger.

The current operating procedure requires that gas samples be taken each quarter from three ZPPR canisters and that an unspecified number of canisters should be opened each year for audit and physical examination of the plates. Selection of cans to be opened and selection of those for sampling are not coordinated and thus do not aid in determining the chemistry occurring in the canister. Also, the gas sampling measurements do not represent the atmosphere of the total population of canisters and the parameters measured, hydrogen, oxygen, and nitrogen are insufficient to determine if the cans are leaky. Moisture content, pressure, and residence time since last opening and closing should also be recorded.

It is recommended that the sampling procedure be changed. Opening 12 canisters quarterly and sampling three of them before opening will result in all the canisters being opened every five years and the atmosphere in $25 \%$ of them being measured, so that the samples will be representative of the atmosphere in all the canisters. The getter is also to be replaced in all cans which have been opened. This will allow a correlation to be developed between concentrations measured with residence time since canister sealing, the conditions of the plates, and condition of the getter. The sampling so far indicates that many of the getters are no longer working and that the plates are hydriding and oxidizing so that the current surveillance and maintenance procedure is flawed. The data tend to indicate (as described in Appendix A) that the getters have a lifetime of five years and this will be verified and/or modified in the proposed surveillance program.

In spite of the fact that several vital pieces of information have not been measured or recorded, the 72 samples taken so far do yield some valuable information on the status of the plates in the canisters. Two samples were lost. All but two of the rest can be classified into the following five groups.

\begin{tabular}{|l|l|l|l|l|}
\hline low $\mathrm{H} 2$ low $\mathrm{O} 2$ & low $\mathrm{H} 2$ high O2 & $0.1<\mathrm{H} 2<1$. low O2 & $1<\mathrm{H} 2<3$ low O2 & $3<\mathrm{H} 2$ low O2 \\
\hline
\end{tabular}

The sample data are included in Table 1 in Appendix A and detailed conclusions are presented there and are summarized here. Upon closing, all canisters are supposed to be fitted with a dessicant and evacuated and overpressured to six psig with ultra dry nitrogen. The green background in the table (low $\mathrm{H} 2$ low O2) indicates canisters with satisfactory atmospheres where getters are working and plate degradation is probably not occurring. Half of the samples taken (36 out of 72) fall in this satisfactory category. Unfortunately, these canisters were probably not the ones opened so the supposed satisfactory condition of these plates has not been verified visually. Also, since the residence time was not recorded, it is possible that some of these satisfactory atmospheres may have been in recently reclosed canisters so that only a short time has elapsed for the reactions to occur. 
The blue background (low H2 high O2) represents canisters (7 out of 72) experiencing significant atmospheric pumping of air into the canister or a canister with an initial air atmosphere. Since the $\mathrm{H} 2$ concentration is low (below $0.1 \%$ ) and all oxygen concentrations are below or slightly exceed that of air, this condition does not represent either a flammable mixture or hydriding. The getter is probably still working since the getters are not a net consumer of oxygen if no hydrogen is present. (See below discussion on the chemistry of the getters for justification of this statement.) Two other samples had measurable hydrogen ( $1 \%$ and $0.7 \%$ respectively) and significant oxygen but are sufficiently far from the flammability limits (4\% $\mathrm{H} 2$ and $20 \%$ oxygen) to represent no hazard.

The other three groups (yellow, mustard, and red backgrounds) suggest hydriding is occurring in the canisters and care should be taken in opening them to prevent flashing of the hydride powder. There were only three canisters with hydrogen concentrations greater than $3 \%(3.3 \%, 3.7 \%$, and $5.4 \%$, respectively). Each had low oxygen so none of these canisters represent a hydrogen flammability hazard while closed and only one of these (the 5.4\%) could present a slight flammability hazard (possible local $\mathrm{H} 2$ concentration greater than $4 \%$ ) when the canister is opened and the atmosphere mixes with air. In all these samples, oxygen concentrations were less than $0.7 \%$ which is considered here to be negligible with respect to a flammability hazard. Most of the oxygen concentrations were $0.2 \%$ or less.

In order to have a combustible mixture, the hydrogen and oxygen concentrations must be in the combustible range. The combustible limits are between $4 \%$ to $75 \%$ hydrogen in air by volume at atmospheric pressure and temperature, (Lewis, 1961, P. 695). The mole fraction of oxygen necessary for combustion can also be determined from this. That is, if the mole fraction of hydrogen, $\mathrm{x}$, is in the range $0.04<x<0.75$, then since the mole fraction of oxygen in air is approximately 0.20 the mole fraction of oxygen, $X$, must be equal to $X=(1-x) \times 0.20$ for the mixture to be combustible. If the mole fraction of oxygen is less than this, the mixture will not be combustible. As an example, if the mole fraction of hydrogen is 0.10 , than the mole fraction of oxygen must be equal to or greater than $(1-0.1) \times 0.20=0.18$. At a hydrogen mole fraction of 0.75 , the mole fraction of oxygen must be 0.05 or greater.

Hydrogen is in the atmosphere indicates that hydriding (the uranium hydrogen reaction) is occurring. Hydrogen remains in the canister gas because this is a slow reaction compared to the uranium moisture reaction. If the sampled canisters with hydrogen concentrations greater than $1 \%$ (mustard and red backgrounds) are assumed to have non functioning getters and hydrating plates (11 out of 72), then one can estimate that of the 231 canisters that $11 / 72 \times 231=35$ canisters have bad getters and plates in this condition. Eleven other canisters had hydrogen concentrations between 0.1 and $1.0 \%$ and may have partially functioning getters. This observation is evidence that the current surveillance program is not performing satisfactorily and that it should be modified to prevent fuel degradation. The most urgent action needed is to replace all getters since bad getters cannot be differentiated from good getters.

One further point should be made. The previous analysis of the data was published in Totemeier, 1997. The concentrations measured at that time were much smaller. Totemeier reports on the bottom of page 6 , "The gas in several canisters was sampled each month and checked for oxygen and hydrogen. No concentrations in excess of 0.1 volume percent were observed. In addition, yearly inspection of the canister containing useable plates has revealed no additional rejects since the use of the getters." Clearly, the situation now is much deteriorated. 


\section{CANISTER CONDITIONS AND ACTIONS TO BE TAKEN BASED ON SAMPLE RESULTS}

\subsection{Actions Which Should be Taken Based on the Gas Samples Taken with the Current Surveillance Procedure}

The current method of choosing which canisters are sampled does not yield information about the other canisters so the actions to be taken are specific to the particular one sampled. All canisters which are opened should be leak tested upon closure to insure that the seal is adequate.

1. Low hydrogen, low oxygen - Take no action. The sample indicates a canister in satisfactory condition.

2. Low hydrogen, significant oxygen. - Replace seal and/or improve sealing of the canister.

3. Low Oxygen, significant hydrogen - Replace getter in the canister taking due care of the flashing of hydride which might occur with the introduction of air. Inspect plates and remove damaged plates. Remove any loose oxide from plates and canister.

4. Oxygen and hydrogen concentrations in the combustible range. - None of the samples were in the combustible range. If a future canister sample were to produce flammable concentrations, then a flammable mixture would exist in the can. Hydride exists and could initiate combustion of the gas mixture. In spite of the fact that the amount of gas available to burn is small and represents a small energy hazard, it would be prudent to not jostle the canister and to open it in an inert hood but this could also probably be accomplished safely in an air environment with flame resistant gloves. Open the canister, replace the getter, and improve the seal. Make certain the canister is evacuated and overpressurized with nitrogen.

\subsection{Actions Which Should be Taken Based on the Gas Samples Taken with the Proposed Surveillance Procedure}

As described in Section 5, the future method of selecting canisters for sampling will produce samples which are representative of all the canisters as a function of residence time. Twelve canisters will be opened each quarter and each of these will have been closed for five years. Previous to opening, three of the 12 canisters are to be sampled with the hydrogen, oxygen, water vapor, nitrogen and pressure determined and reported. The three samples should show the same results since they have been subjected to the same conditions. The only reasons that the results should be different is if one of the canisters did not seal or if the canisters were not evacuated and overpressured with nitrogen when originally sealed. If the results differ for any other reason, then this procedure will have to be re-evaluated. Upon opening all twelve canisters, the condition of the plates and the dessicant should be recorded. If all the plates are in a satisfactory condition, all the desiccants should be replaced and the canisters resealed and repressurized. If any hydriding has occurred then the replacement time must be decreased. Hydrogen in the sample is also evidence of the need to reduce the residence time. The procedure for determining the decrease in the time will begin by opening the group of canisters which have been closed only 4.75 years. If they are satisfactory, then that is the residence time which should be used. If not, then this process will be continued until all the canisters sampled and opened show no signs of hydriding. 
The results of each quarterly inspection are to be evaluated by an analyst to make certain that nothing unexpected is occurring. The time between analyst evaluations may be extended if all the results are as expected for a year. An annual report should be written to document the annual analysis.

\subsection{Possible Canister Conditions}

The following is a list of possible canister atmospheres and the consequences of each, including those not expected to occur.

Situation 1: Significant hydrogen $(1 \%<\mathrm{H} 2<8 \%)$. No significant oxygen. May contain moisture. No moisture measurements have been made so far.

Hydriding has continued and hydride dust is now present in the canister. Little oxygen is present in the atmosphere since any oxygen brought in by inleaking air will quickly react with the hydride to form oxide plus water according to the reaction

$$
2 \mathrm{UH}_{3}+3.5 \mathrm{O}_{2} \rightarrow 2 \mathrm{UO}_{2}+3 \mathrm{H}_{2} \mathrm{O}
$$

Evidence of hydriding: The above reaction proceeds rapidly so no oxygen would be present if the hydride is forming. Thus, if oxygen is present, this is evidence that there is no hydride. Some moisture could be in the gas phase. This moisture would either come from the above reaction, initial moisture, or moisture brought in with inleaking air. Hydrogen is produced due to the presence of moisture by the reaction

$$
\mathrm{U}+2 \mathrm{H}_{2} \mathrm{O} \rightarrow \mathrm{UO}_{2}+2 \mathrm{H}_{2}
$$

Hydrogen in the gas phase is also likely since the hydriding reaction as shown in the following equation, is slow.

$$
2 \mathrm{U}+3 \mathrm{H}_{2} \rightarrow 2 \mathrm{UH}_{3}
$$

(Equation 2 of Solbrig, 1994)

So hydrogen in the gas is evidence that the getter is no longer working and that it needs to be replaced to stop further hydriding.

Possible Hazards: Since no oxygen is available, no sudden deflagration is possible unless the canister is opened in air. So no hazard exists as long as the canister is not opened. There is no safety concern about this canister as long as it is not being sampled. The undesirable effect is that the plates are being eroded. Erosion is used here to mean that the plates are disappearing because the hydride is formed, flakes off, and then becomes oxidized.

If this happens to be a canister which is sampled, then this is cause for replacing the getter. Care should be taken when moving the canister so that the hydride is not dispersed in the canister atmosphere. It would be prudent when opening the canister to do it in an inert atmosphere to prevent flashing of the hydride with the introduction of air. The usual procedure of cleaning the plates should be done and a new getter inserted.

Situation 2: Large amount of hydrogen $(\mathrm{H} 2>8 \%)$, no significant oxygen. May be significant moisture. 
No samples have exhibited large hydrogen concentrations. The largest hydrogen percentage observed is $5.4 \%$. The available uranium area appears to be large enough to react enough hydrogen to form the hydride to keep the hydrogen percent low. If uranium surface was not available for this reaction, then hydrogen would not have formed in the first place. So it is unlikely that such a high hydrogen concentration would occur.

If the hydrogen levels are ever observed greater than $8 \%$ then it is possible when the canister is opened that a flammable mixture (4\%) could be attained when the outside air is mixed with gas in the canister. As with Situation 1, hydride would be present. The uranium hydride would ignite and probably ignite the mixture. It is unlikely that the uranium metal would by ignited by this event since the hydride does not adhere to the uranium. This canister should be opened in an inert atmosphere or carefully with flame retardant gloves in an air hood.

Situation 3a: Significant amount of oxygen in the atmosphere but less than half of atmospheric, no significant moisture, no significant hydrogen, atmospheric pressure: Large leak area. Air is being pumped and diffusing in profusely. Getter is still working since there is no moisture. The oxygen remains because there is no hydrogen to react with it. Any uranium exposed is still oxidizing but a protective layer is forming or completely formed. Any small amount of hydrogen forming from the small moisture is being vented from the canister.

Situation 3b: Significant amount of oxygen. Significant moisture. No significant hydrogen. Moisture getter $(\mathrm{LiH})$ is not working. Plates are being oxidized by the moisture. The hydrogen produced is reacting with the oxygen via the Pd catalyst so it is still working.

Situation 3c: Significant amount of oxygen. Significant moisture. Some hydrogen. Moisture getter is not working. Hydrogen getter is not working either. Any hydrogen formed is diffusing out through a large canister leak.

Replace the O-ring. In $3 \mathrm{~b}$ and $3 \mathrm{c}$, also replace the getter. May want to transfer good plates to a better canister or improve the O-ring seal to preserve them from further oxidation.

Situation 3d: High concentrations of oxygen. Close to that of air. These canisters may have been filled with air initially or are so leaky that air has replaced the nitrogen. Containers which are air filled are probably leaky enough that the hydrogen formed leaks out. This is essentially a container which is vented. This venting removes the danger of hydrogen air flammability and hydriding of the plates but allows oxidizing of the uranium with any moisture which comes into the canister.

Situation 4: Hydrogen and Oxygen in the gas space in the flammable range:

This situation has not been observed in any of the measurements. This is a possible flammable situation if a spark is generated by the hydride reacting with the oxygen. The corrosion cycle postulated in Solbrig, 1994 indicates this can't happen since even if the getter is not working any oxygen will react with the hydride, producing oxide and hydrogen. The hydrogen will then hydride the HEU slowly and the process will continue again until only hydrogen remains in nitrogen gas.

Only two of the gas samples taken showed any significant amount of hydrogen in the presence of significant oxygen. The lower flammability limit is $4 \%$ hydrogen with $96 \%$ air (air is $20 \%$ oxygen, $80 \%$ nitrogen). The two samples were $1 \% \mathrm{H}_{2} 1.5 \% \mathrm{O}_{2}$ and $0.65 \% \mathrm{H}_{2} 16 \% \mathrm{O}_{2}$ so both were significantly below this flammability limit. 
Situation 5: A canister loaded with failed plates: The failed plates probably all have been exposed to air when they were put in the canister. There would be no gross amount of hydride on the failed plates left since they had already been exposed to air and the oxygen reacts immediately with the hydride to form oxide and release hydrogen. The only hydride in the canister would be from moisture in the nitrogen cover gas added when it was closed or from moisture in the inleaking air. Thus the amount of hydride in a canister with all failed plates should not be greater than in a normal canister with a failed getter. 


\section{ATMOSPHERE OF THE CANISTERS AND FUNCTION OF THE GETTERS}

The getter used in the canisters is a packet containing an unsaturated hydrocarbon with a palladium catalyst and lithium hydride. The hydrocarbon is 1.4-bis (phenylethynyl) benzene (referred to as DEB), which contains two carbon-carbon triple bonds. The getter removes hydrogen, water vapor, and oxygen (if hydrogen is present as described later). The scavenging of hydrogen by the DEB via the Pd catalyst is irreversible. The lithium hydride material is present to scavenge any water vapor present in the environment or any produced in the hydrogen water reaction. The Pd is needed to catalyze the reaction of hydrogen with the DEB material. (Totemeier, 1997) and hydrogen with oxygen.

\subsection{Sources of Gases in the Canisters}

Upon inspection of an opened container and then closure, the canister is first evacuated, then overpressured with very dry nitrogen, to 6 psig. If the canister is leaky, the nitrogen overpressure will leak out. With normal fluctuations in atmospheric pressure, an atmospheric pressure rise will allow some air (with moisture) to leak into the canister and mix with the nitrogen. A decrease in atmospheric pressure will cause some outleakage, leaving behind some oxygen and moisture. This is referred to here as atmospheric pumping. Without a getter in the canister, moisture and oxygen brought into the canister by the mechanism will allow the corrosion cycle to proceed until all the oxygen is reacted leaving uranium oxide and uranium hydride and only nitrogen in the gas.

Nitrogen in the canister comes from the initial overpressure and any in-leakage from atmospheric pumping, if the overpressure nitrogen leaks down to atmospheric pressure. The canister pressure should be measured in future surveillance operations to determine if the canister has leaked. reaction

Hydrogen in the canisters originates solely from the reaction of moisture with uranium in the

$$
\mathrm{U}+2 \mathrm{H}_{2} \mathrm{O} \rightarrow \mathrm{UO}_{2}+2 \mathrm{H}_{2} .
$$

Moisture only comes from initial loading, atmospheric pumping, and the reaction of hydrogen formed in the above reaction with available oxygen via the Pd catalyst in the getter. Moisture should be measured in future surveillance operations.

Oxygen only comes from in-leakage. The only way for oxygen to be in the atmosphere in a canister is from air inleakage from atmospheric pumping or the initial vacuum.

\subsection{Requirement of Getter Placement in all Canisters and Replacement Period}

Storage in an air atmosphere will produce a protective oxide layer on the uranium to slow down the oxidation reaction with moisture but this does allow oxidation of the uranium. To prevent any oxidation, the plates were stored with an inert gas overpressure. A protective oxide layer is not formed when uranium is stored in an inert gas so that any moisture in an inert gas is not impeded from reacting with the uranium. So ultra dry nitrogen is used for overpressuring the canisters. Still, enough moisture is brought into the canister to require a getter to be used to absorb any moisture brought in. Ritchie (1981) presents the reaction rates for both oxygen and water vapor with uranium and shows that the reaction rate of the water vapor with uranium is faster than oxygen. It is very difficult to obtain a perfectly dry gas. Attempts 
to use argon as the cover gas have proven unsuccessful because of the difficulty of obtaining it perfectly dry.

To protect the plates from hydriding, the moisture must be kept out of the canisters or absorbed with the getter. The getter is an irreversible hydrogen-oxygen-water getter. The recommendation in this report is to assume it is good for five years and then check to see that it actually lasts that long by examining canisters with a residence time of 5 years and working backwards to shorter residence times if 5 years is unsatisfactory. Other methods of determining the usable lifetime are possible. It may be worth performing a small experiment to see how long it would take to saturate a getter.

According to Section 8.1 of ZPPR OI-012 following Step 12, the following note is included.

NOTE There is no easy method to determine if the material in any getter bag has become saturated and needs to be replaced. As the getter material in a bag reacts, the loose granular feel of the material may change to a hard solid. Trends will be observed; when the hydrogen and/or oxygen concentrations become $>1 \%$, the getter material will be replaced. A getter bag will also be replaced if the bag material shows signs of deterioration.

This is the reason that the getter bags must be replaced on a periodic basis rather than when they look as if they are bad.

Also, there is a problem with the ZPPR Operating instruction 5.3.4. It states that "Canisters designated to hold rejected plates must have getter bags placed in them and then be sealed and backfilled with nitrogen." This mav be a misstatement since getters should be placed in all canisters to protect the plates not just in canisters with rejects.

\subsection{Important Note: Getter does not Consume Oxygen if There is no Hydrogen}

The following three equations from Solbrig, 1994 show how the getter consumes water, oxygen, and hydrogen.

$$
\begin{aligned}
& \mathrm{H}_{2} \mathrm{O}+\mathrm{LiH} \rightarrow \mathrm{LiOH}+\mathrm{H}_{2} \\
& 2 \mathrm{H}_{2}+\mathrm{O}_{2} \rightarrow 2 \mathrm{H}_{2} \mathrm{O} \text { (via Pd Catalyst) } \\
& 2 \mathrm{H}_{2}+(-\mathrm{C} \equiv \mathrm{C}-) \rightarrow\left(-\mathrm{CH}_{2} \equiv \mathrm{CH}_{2}-\right) \text { (via Pd Catalyst) }
\end{aligned}
$$

Water is consumed in the first reaction by combining with $\mathrm{LiH}$ to produce $\mathrm{LiOH}$ and $\mathrm{H}_{2}$. In the second, hydrogen produced in the first and oxygen are converted to water. Thus the first plus the second reactions are a net consumer of water and oxygen but not of hydrogen. Net consumption of hydrogen is accomplished with the third reaction. This also shows that if no hydrogen is present, the oxygen will not be consumed by the getter and is still left to potentially oxidize the plates.

This conclusion is illustrated in Table 1 of the Appendix. It shows that five of the canisters have significant oxygen concentrations with the maximum being $21.3 \%$ (slightly greater than ambient but presumably within measurement error bounds of ambient). In all five cases, there was a negligible amount of hydrogen so the oxygen was not consumed. In order for the oxygen concentration to be as high as atmospheric, the canister leaks must be large enough that all the nitrogen has been replaced with air or that the canister was initially filled with air. 
In summary, if the $\mathrm{LiH}$ is not functional but the DEB portion is, then the atmosphere will have moisture in it, and oxygen, but little or no hydrogen. If the $\mathrm{LiH}$ is functional, but the DEB is not, the atmosphere will have hydrogen, little or no moisture, and little or no oxygen. If both are functional, the atmosphere will have no moisture, no hydrogen, but can have oxygen.

A question was raised about the possibility of consuming oxygen by reaction with LiH. Properties of Lithium Hydride: flammable, white, translucent solid; decomposes at $850 \mathrm{C}$; reacts violently with water to yield hydrogen and lithium hydroxide; used as a hydrogen source or reducing agent to prepare other hydrides amides and $2 \mathrm{H}$ isotopic compound, as a shielding material for thermal neutrons. Auto-ignition temperature: $200^{\circ} \mathrm{C}$. Since the autoignition temperature is so high, it appears that the $\mathrm{LiH}$ oxygen reaction is slow at room temperature and would not be expected to consume oxygen.- It may also develop a protective coating as the uranium oxide does. 


\section{DESCRIPTION OF THE NEW SURVEILLANCE PROGRAM WHICH MINIMIZES DAMAGE TO THE ZPPR PLATES}

The current program is not accomplishing the goal of preventing further damage to the plates so the following modification is recommended. Due to the failure of the getter in many of the canisters and the difficulty in determining if a getter is functioning, the getters need to be changed out on a periodic basis. Based upon the data taken so far (see the discussion in Appendix A just before Table 1), this period is estimated to be five years. The expanded measurement program recommended below could cause this period to be changed.

To initiate the new operating procedure and to halt further degradation of the plates, all the canisters with residence times greater than four years, longest first, should be opened, the getters replaced, and then closed, evacuated and overpressured to 6 psig with nitrogen. If the residence times of the canisters cannot be identified, then all canisters should be processed with the suspected longest residence time processed first. If the residence time of canisters is not determinable, canisters selected for opening should be based on their sequential numbering identification.

Forty-eight canisters will be opened each year (twelve each quarter) so that each of the 231 canisters will be opened approximately once every five years. Before opening, three of the 12 canisters will sampled and hydrogen, oxygen, water vapor, and nitrogen concentrations determined in addition to the pressure in the canister. The pressure is measured and recorded to determine the degree of leakage during the residence time. A pressure near atmospheric indicates that oxygen and water vapor have probably entered through atmospheric pumping. The date of opening and canister ID should be recorded. After these results are obtained and reported, the three sampled canisters plus nine others will be opened and the status of the plates observed and recorded. Sampling now represents how a canister has progressed for a five year period (or shorter, depending if all must be processed initially). Thus, $25 \%$ of all the canisters will be sampled over a 5 year period.

The sampling is no longer random, but representative of how each canister has behaved over five years. If the sample results are similar, three samples, along with visual inspection of the plates in all twelve, will be sufficient to estimate the atmosphere condition of those not sampled. If the sample and plate condition are significantly different, then further analysis will be required. Differences may be due to inleakage, mistakes in initial fill of nitrogen, and/or defective getters. The condition of the plates in the canisters sampled will be correlated with the gas samples. The getter in each of the opened canisters will be replaced before the canister is resealed. If the plates in the canisters with five years residence time are hydrided, then the getters will have to be replaced more often. If all the getters have to be replaced initially, then sample and plate condition information will be obtained as a function of residence time up to the five years.

The procedure for handling hydrided or failed plates will remain the same. It consists of: removing any hydride material, wrapping damaged plates, and storing them in a damaged plate container. The O-ring is replaced if it appears to be damaged or if the canister will not hold pressure. The canisters are pressurized with ultra dry nitrogen to 6 psi. The pressure should be recorded upon initial fill and after 24 hours to make sure the canister does not have a significant leak. 
An analysis of the data should be done once a year and a report written which projects the condition of all the canisters and plates and concludes whether or not corrosion is continuing. There is apparently no current requirement to analyze the data taken. The analysis previous to this on was reported in 1997 (Totemeier, 1997). The lack of analysis of the data has allowed the plates to hydride in many of the canisters. The lack of getter replacement has caused this deterioration in the plates.

This modified procedure requires no additional samples than the current procedure but yields significantly more information. More canister openings may be required, more getter replacement is required, and more frequent analysis is required. 


\section{CONCLUSIONS}

The sample data indicate that hydriding could be occurring in 35 and, perhaps, starting in 35 more of the uranium fuel plate canisters. The getters in all the canisters are suspect and should be replaced soon to prevent further hydriding. If canister residence time can be determined, then the longest resident time getters should be replaced first. The surveillance procedure needs to be modified as described in the above report. The getters should be replaced at each inspection ensuring that no getter is used more than five years. The sample and plate condition data should be analyzed each year and a report written on the conclusion made on the adequacy of the surveillance procedure. Further modifications should be made if it appears hydriding is still occurring. 


\section{REFERENCES}

1. Lewis, B., and Von Elbe, G., Combustion, Flames, and Explosions of Gases, Academic Press, New York, 1961.

2. Ritchie, A. G., "A Review of Rates of Reaction of Uranium with Oxygen and Water Vapor at Temperatures up to 300 C," J. of Nuclear Materials, 102(1981), p. 170-182.

3. Solbrig, C. W., Krsul, J. R., and Olsen, D. N., "Pyrophorocity of Uranium in Long Term Storage Environments," Proceedings of DOE Spent Nuclear Fuel: Challenges and Initiatives, ANS Topical Meeting, Salt Lake City, Dec. 13-16, 1994.

4. Totemeier, T. C., Pahl, R. G., Hayes, S. L., and Frank, S. M., Metallic Uranium ZPPR Fuel: Corrosion Characteristics and Corrosion Product Oxidation Kinetics, Argonne National Laboratory Report ANL-98/11, UC-504, October 1997.

5. ZPPR Operating Instructions, Fuel-Surveillance Activities For Nonoperational Standby, ZPPR-OI-012, Rev. 0c, 5/21/04. 
Appendix A

\section{Detailed Comments on the Data Sheets}




\section{Appendix A}

\section{Detailed Comments on the Data Sheets}

There are 231 canisters (according to Solbrig, 1994). There is no record of how many of these have been opened for inspection.

Over 8.5 years (1996 thru 2004), 72 gas samples were taken from the canisters, 2 of the samples were lost, leaving 70. According to the Operating Instructions (ZPPR, 2004), three samples should be taken each quarter. That would have resulted in $8.5 \times 4 \times 3=102$ samples. There were 8 canisters that were sampled twice and 3 that were sampled 3 times so only $72-14=58$ canisters were samples. In the last two years, as of Dec, 2004, very few samples were taken. None were taken in 2003 and only one set of three were taken in 2004.

The current method of taking the three samples every quarter are insufficient to determine the present status of all 231 canisters or the trend in the concentrations. Without concentrations versus residence time, it is impossible from the sample data to conclude that all the containers are behaving the same so that the current procedure is not producing samples representative of all the canisters. In the previous analysis report (Totemeier, 1997), all of the oxygen and hydrogen concentrations measured were less that 0.1 and no hydriding was observed. These satisfactory conditions no longer exist.

Only hydrogen, oxygen and nitrogen were measured which is insufficient. Moisture content and pressure should be determined and recorded as well. The condition of the plates, (rejects, etc) and any indication of powder (oxide or hydride) should be recorded. The 2004 operating instructions (ZPPR, 2004) for the ZPPR fuel surveillance require documentation of all actions taken but the data sheets previous to this did not record these actions. Only one set of samples were taken in 2004 and this is the only time that the number of reject plates and pressure were measured. There is no record of what canisters have been opened so that the gas samples taken can represent either short or long time since closure so even the samples showing negligible hydrogen or oxygen might not indicate a good getter and insignificant leakage.

There were 22 samples with $\mathrm{H} 2$ greater that $0.1 \%$. Of these, 11 were greater than $1 \%$. Of these, 3 were greater than $3 \%$. The highest was $5.4 \%$ in all except two of these cases, the samples had oxygen less than $0.7 \%$ which is considered here to be negligible with respect to a flammability hazard. Most of the oxygen concentrations were $0.2 \%$ or less. In all these cases, it is considered that the hydrogen and water getters are no longer working and need to be replaced in order to prevent further hydriding. The reason there is not significant oxygen in these canisters is that the amount of hydriding is sufficient to consume all the oxygen. That is, as soon as any hydride is formed, it quickly reacts with any oxygen to produce uranium oxide and hydrogen. The hydrogen then reacts slowly with uranium to produce uranium hydride which is then again available to react with any oxygen. The hydrogen always ends up as hydride (See Solbrig, 1994 for description of this corrosion cycle).

Solbrig, 1994 concluded that the identification of hydrogen and the depletion of oxygen in canisters confirms that corrosion is occurring even in canisters containing only non-deformed plates.

There were two samples that had more than insignificant amounts of both hydrogen and oxygen. One sample had $1 \% \mathrm{H} 2$ with $1.5 \% \mathrm{O} 2$. The second had $0.65 \% \mathrm{H} 2$ and $16 \% \mathrm{O} 2$. Neither of these present a flammability hazard. 
There were 9 samples with significant oxygen. With the exception of the above two, none had any significant amount of hydrogen (all were $0.04 \%$ or less). And the hydrogen levels in the above two are rather small. The oxygen percentages were 1.2, 1.5, 2.66, 2.9, 8.5, 12.4, 16, 16, and 21.3. The only source of oxygen should be inleaking of air. Inleaking air also brings in moisture. Since there was essentially no hydrogen in these samples, the getter was working by taking out moisture (LiH) and hydrogen (DEB). Since there is no hydrogen, the oxygen cannot react with it via the palladium catalyst in getter. So the oxygen remains to react with uranium until the exposed uranium is covered with a protective oxide layer. The increased oxygen percentages apparently correspond to increasingly leaky canisters but it is difficult to understand how the higher oxygen percentages could occur from atmospheric pumping, especially the $21.3 \%$ since that is slightly higher than ambient air. Since this sample was taken from a canister that contained all reject plates, perhaps there was no attempt to backfill this with nitrogen so it may have started out with ambient air. The higher than ambient oxygen concentration may be due to measurement error. In the future, it is recommended that the actions taken to replace the getter, evacuate the canisters, and overfill them with nitrogen be recorded.

The remainder of the canister samples showed no significant hydrogen or oxygen and are considered satisfactory.

Examination of Table 1 shows that there is very little hydrogen in the samples from the first samples reported on (06/07/96) until the 08/04/97 samples. This observation and statements in Solbrig, 1994 and Totemeier, 1997 indicates that the getters were probably all working until 1997. Assuming that the getters were placed in the canisters two years before the Solbrig, 1994 publication indicates the getters may function for five years. However, there were many samples taken after this time that also showed low hydrogen readings so possibly many of the getters lasted longer than this.

Table 1. Sample data and classification.

\begin{tabular}{|c|c|c|c|c|c|c|c|c|}
\hline Date & $02 / 24 / 04$ & $11 / 01 / 02$ & $09 / 30 / 02$ & $09 / 20 / 02$ & $09 / 06 / 02$ & $06 / 22 / 01$ & $03 / 28 / 01$ & $12 / 18 / 00$ \\
\hline $\begin{array}{l}\text { Canister } \\
\text { ID }\end{array}$ & $\begin{array}{c}89 \text { Galso } \\
2 / 2 / 00\end{array}$ & 89B & $88 \mathrm{~V}$ & $88 \mathrm{~S}$ & $\begin{array}{c}88 \text { Malso } \\
7 / 28 / 00\end{array}$ & $88 \mathrm{~F}$ & $88 \mathrm{Q}$ & 880 \\
\hline Hydrogen & 0.43 & $\begin{array}{c}\text { Lost } \\
\text { sample }\end{array}$ & 1.33 & 0.1 & $<0.05$ & $<0.003$ & ND & $<0.05$ \\
\hline Oxygen & 0.12 & $\begin{array}{c}\text { Lost } \\
\text { sample }\end{array}$ & 0.11 & 0.65 & $<0.07$ & 0.05 & 0.1 & 0.11 \\
\hline Rej Plates & 3 & & & & & & & \\
\hline $\begin{array}{c}\text { Canister } \\
\text { ID }\end{array}$ & $89 \mathrm{H}$ & $\begin{array}{l}\text { 89E See } \\
12 / 09 / 99\end{array}$ & $\begin{array}{l}\text { 89A See } \\
7 / 29 / 98\end{array}$ & $88 \mathrm{~T}$ & $88 \mathrm{H}$ & $88 \mathrm{R}$ & $88 \mathrm{P}$ & $88 \mathrm{C}$ \\
\hline Hydrogen & 0.31 & 1 & ND & 1.87 & 1.3 & $<0.003$ & ND & $<0.05$ \\
\hline Oxygen & 0.34 & 1.5 & $<0.07$ & $<0.1$ & $<0.07$ & 0.7 & 0.3 & 0.01 \\
\hline Rej Plates & 2 & & & & & & & \\
\hline $\begin{array}{l}\text { Canister } \\
\text { ID }\end{array}$ & $\begin{array}{l}89 \mathrm{~K} \text { See } \\
11 / 19 / 97\end{array}$ & $89 \mathrm{Q}$ & $\begin{array}{c}89 \mathrm{M} \text { See } \\
7 / 29 / 98\end{array}$ & $\begin{array}{c}88 \text { U See } \\
7 / 22 / 98\end{array}$ & $\begin{array}{l}880 \text { See } \\
12 / 18 / 00\end{array}$ & $88 \mathrm{G}$ & $88 \mathrm{E}$ & $88 \mathrm{D}$ \\
\hline Hydrogen & 0.2 & 0.35 & $<0.01$ & 0.98 & $<0.05$ & $<0.003$ & ND & $<0.05$ \\
\hline Oxygen & 0.089 & $<0.1$ & 0.206 & $<0.1$ & $<0.07$ & 0.09 & 0.4 & 0.07 \\
\hline Rej Plates & 7 & & & & & & & \\
\hline $\begin{array}{l}\text { Color } \\
\text { Code }\end{array}$ & $\begin{array}{l}\text { low } \mathrm{H} 2 \\
\text { low } \mathrm{O} 2\end{array}$ & $\begin{array}{l}\text { low H2 } \\
\text { high O2 }\end{array}$ & $\begin{array}{c}.1<\mathrm{H} 2<1 \\
\text { low O2 }\end{array}$ & $\begin{array}{l}1<\mathrm{H} 2<3 \\
\text { low } \mathrm{O} 2\end{array}$ & $\begin{array}{l}3<\mathrm{H} 2 \\
\text { low } \mathrm{O} 2\end{array}$ & & & \\
\hline
\end{tabular}


Table 1. (continued).

\begin{tabular}{|c|c|c|c|c|c|c|c|c|}
\hline Date & $07 / 28 / 00$ & $05 / 08 / 00$ & $02 / 02 / 00$ & $12 / 1 / 99$ & 09/01/98 & $07 / 29 / 98$ & $07 / 22 / 98$ & $04 / 10 / 98$ \\
\hline $\begin{array}{l}\text { Canister } \\
\text { ID }\end{array}$ & $88 \mathrm{~N}$ & & $89 \mathrm{H}$ & $89 \mathrm{D}$ & $72 \mathrm{~S}$ & 89B & & $71 \mathrm{~N}$ \\
\hline Hydrogen & ND & ND & $<0.00001$ & 0.000014 & 3.3 & $<0.35$ & $\begin{array}{c}\text { Lost } \\
\text { sample }\end{array}$ & 1.26 \\
\hline Oxygen & 21.3 & 0.1 & 0.65 & 0.13 & 0.5 & 0.2 & $\begin{array}{c}\text { Lost } \\
\text { sample }\end{array}$ & 0.26 \\
\hline Rej Plates & $\begin{array}{c}\text { All } \\
\text { Canister }\end{array}$ & & & & & & & \\
\hline $\begin{array}{c}\text { Canister } \\
\text { ID }\end{array}$ & $88 \mathrm{M}$ & & $89 \mathrm{R}$ & $89 \mathrm{E}$ & $72 \mathrm{G}$ & $89 \mathrm{~A}$ & $88 \mathrm{U}$ & $71 \mathrm{~T}$ \\
\hline Hydrogen & ND & ND & $<0.00001$ & $<0.000009$ & 0.08 & $<0.041$ & 3.7 & 0.1 \\
\hline Oxygen & 0.15 & 0.1 & 0.16 & 0.1 & 0.1 & 0.1 & 0.1 & 0.14 \\
\hline \multicolumn{9}{|l|}{ Rej Plates } \\
\hline $\begin{array}{c}\text { Canister } \\
\text { ID }\end{array}$ & $88 \mathrm{~B}$ & & $\begin{array}{l}89 \text { G See } \\
10 / 22 / 96 \\
\end{array}$ & $\begin{array}{c}890 \text { See } \\
6 / 7 / 96 \\
\end{array}$ & $72 \mathrm{~T}$ & $89 \mathrm{M}$ & $72 \mathrm{P}$ & $71 \mathrm{~B}$ \\
\hline Hydrogen & ND & ND & $<0.00001$ & $<0.000009$ & 5.4 & $<0.042$ & 0.5 & $<0.03$ \\
\hline Oxygen & 0.17 & 1.2 & 0.11 & 2.66 & 0.2 & 0.1 & 0.2 & 0.05 \\
\hline Rej Plates & & $\begin{array}{c}\text { ?Bad } \\
\text { Samples }\end{array}$ & & & & & & \\
\hline
\end{tabular}

Table 1. (continued).

Date
\begin{tabular}{|c|c|c|c|c|c|c|c|c|}
\hline $\begin{array}{c}\text { Canister } \\
\text { ID }\end{array}$ & $71 / 30 / 98$ & $11 / 19 / 97$ & $08 / 04 / 97$ & $04 / 22 / 97$ & $01 / 29 / 97$ & $10 / 22 / 96$ & $07 / 12 / 96$ & $06 / 07 / 96$ \\
\hline Hydrogen & 0.46 & 0.19 & 0.48 & $<0.035$ & $<0.04$ & $<0.033$ & $<0.032$ & $<0.03$ \\
\hline Oxygen & 0.2 & 0.1 & 0.3 & 0.2 & 16 & 0.14 & 0.17 & 0.1 \\
\hline Rej Plates & & & & & & & & \\
\hline $\begin{array}{c}\text { Canister } \\
\text { ID }\end{array}$ & $71 \mathrm{D}$ & $89 \mathrm{~K}$ & $90 \mathrm{~L}$ & $50 \mathrm{D}$ & $88 \mathrm{~W}$ & $89 \mathrm{G}$ & $90 \mathrm{G}$ & $89 \mathrm{C}$ \\
\hline Hydrogen & 0.09 & 0.24 & 1.3 & $<0.037$ & 0.1 & $<0.035$ & $<0.033$ & $<0.03$ \\
\hline Oxygen & 0.1 & 0.2 & 0.2 & 12.4 & 0.1 & 0.12 & 0.14 & 8.5 \\
\hline $\begin{array}{c}\text { Rej Plates } \\
\text { Canister } \\
\text { ID }\end{array}$ & $71 \mathrm{M}$ & $89 \mathrm{~L}$ & & $50 \mathrm{E}$ & $49 \mathrm{~N}$ & $89 \mathrm{~S}$ & $90 \mathrm{U}$ & $89 \mathrm{O}$ \\
\hline Hydrogen & 0.6 & 0.68 & 2.2 & $<0.036$ & $<0.03$ & $<0.035$ & $<0.032$ & $<0.03$ \\
\hline Oxygen & 0.1 & 16 & 0.1 & 0.1 & 0.1 & 0.12 & 0.14 & 2.9 \\
\hline Rej Plates & & & & & & & & \\
\hline
\end{tabular}

Sampling the same canisters: Samples taken on the same canisters were looked at to see if any conclusions could be drawn about the increase in hydrogen concentration with residence times.

Abstracted from Table 1 they are shown in Table 2 below. The first four duplicates, $(88 \mathrm{M}, 88 \mathrm{O}, 89 \mathrm{~A}$, and $89 \mathrm{M}$ ), are all green shaded. Both the earlier and later samples in these duplicates show low hydrogen and oxygen concentration. No increase is observed in either concentration demonstrating that there is little leakage and that the getters are working. The fifth duplicate was lost. The sixth duplicate shows significant oxygen with negligible hydrogen with little change in either concentration over three years. The seventh sample shows a large early hydrogen percent and a later much smaller one. Possibly, this 
canister was opened and refilled with nitrogen between these two samples. The eighth duplicate (89K) shows a small amount of hydrogen in both the early and the later sample. The last three multi-samples were triplicates. The $9^{\text {th }}$ and $10^{\text {th }}$ multi-samples show an increase in hydrogen concentration from the early to the later samples but the mid sample showed a minimum. The $11^{\text {th }}$ multi-sample shows a larger increase from the first to the last but again the middle one showed a minimum. The last also showed significant oxygen $(1.5 \%)$. Perhaps the explanation of the low middle hydrogen reading, in all three of the triplicates, is that the canisters were opened before the middle sample and the getters replaced.

Table 2. Results of multiple samples from the same canisters.

\begin{tabular}{|c|c|c|c|c|c|c|}
\hline Date & 09/06/02 & $07 / 28 / 00$ & 09/06/02 & $12 / 18 / 00$ & 09/30/02 & $07 / 29 / 98$ \\
\hline Can & $88 \mathrm{M}$ & $88 \mathrm{M}$ & 880 & 880 & 89A & 89A \\
\hline $\mathrm{H} 2$ & $<0.05$ & ND & $<0.05$ & $<0.05$ & ND & $<0.041$ \\
\hline $\mathrm{O} 2$ & $<0.07$ & 0.15 & $<0.07$ & 0.11 & $<0.07$ & 0.1 \\
\hline Date & $09 / 30 / 02$ & $07 / 29 / 98$ & $11 / 01 / 02$ & $07 / 29 / 98$ & $12 / 01 / 99$ & $06 / 07 / 96$ \\
\hline Can & $89 \mathrm{M}$ & $89 \mathrm{M}$ & 89B & $89 \mathrm{~B}$ & 890 & 890 \\
\hline $\mathrm{H} 2$ & $<0.01$ & $<0.042$ & Lost & $<0.35$ & 0.000009 & $<0.03$ \\
\hline $\mathrm{O} 2$ & 0.206 & 0.1 & Lost & 0.2 & 2.66 & 2.9 \\
\hline
\end{tabular}

\begin{tabular}{|c|c|c|l|c|c|l|l|l|}
\hline Date & $09 / 20 / 02$ & $07 / 22 / 98$ & & $02 / 24 / 04$ & $11 / 19 / 97$ & & & \\
\hline Can & $88 \mathrm{U}$ & $88 \mathrm{U}$ & & $89 \mathrm{~K}$ & $89 \mathrm{~K}$ & & & \\
\hline $\mathrm{H} 2$ & 0.98 & 3.7 & & 0.2 & 0.24 & & & \\
\hline $\mathrm{O} 2$ & $<0.1$ & 0.1 & & 0.089 & 0.2 & & & \\
\hline
\end{tabular}

\begin{tabular}{|c|c|c|c|l|c|c|c|c|}
\hline Date & $02 / 24 / 04$ & $02 / 02 / 00$ & $06 / 07 / 96$ & & $02 / 24 / 04$ & $02 / 02 / 00$ & $10 / 22 / 96$ & \\
\hline Can & $89 \mathrm{H}$ & $89 \mathrm{H}$ & $89 \mathrm{H}$ & & $89 \mathrm{G}$ & $89 \mathrm{G}$ & $89 \mathrm{G}$ & \\
\hline $\mathrm{H} 2$ & 0.31 & $<0.00001$ & $<0.03$ & & 0.43 & $<0.00001$ & $<0.035$ & \\
\hline $\mathrm{O} 2$ & 0.34 & 0.65 & 0.1 & & 0.12 & 0.11 & 0.12 & \\
\hline
\end{tabular}

\begin{tabular}{|c|c|c|c|l|l|l|l|l|}
\hline Date & $11 / 01 / 02$ & $12 / 01 / 99$ & $11 / 19 / 97$ & & & & & \\
\hline Can & $89 \mathrm{E}$ & $89 \mathrm{E}$ & $89 \mathrm{E}$ & & & & & \\
\hline $\mathrm{H} 2$ & 1 & 0.000009 & 0.19 & & & & & \\
\hline $\mathrm{O} 2$ & 1.5 & 0.1 & 0.1 & & & & & \\
\hline
\end{tabular}

\begin{tabular}{|l|c|c|c|c|c|c|c|c|}
\hline & $\begin{array}{l}\text { low } \mathrm{H} 2 \\
\text { low } \mathrm{O} 2\end{array}$ & $\begin{array}{c}\text { low } \mathrm{H} 2 \\
\text { high } \mathrm{O} 2\end{array}$ & $\begin{array}{c}.1<\mathrm{H} 2<1 . \\
\text { low } \mathrm{O} 2\end{array}$ & $\begin{array}{c}1<\mathrm{H} 2<3 \\
\text { low } \mathrm{O} 2\end{array}$ & $\begin{array}{c}3<\mathrm{H} 2 \\
\text { low } \mathrm{O} 2\end{array}$ & & & \\
\hline
\end{tabular}

So, in conclusion, samples taken on the same canisters did not show significant evidence of increasing hydrogen and oxygen concentrations with residence time. 